\title{
The relationship between vapour pressure excess and air change rates in bedrooms: a pilot study
}

\author{
Jalal Ahmed ${ }^{\mathrm{a} *}$, Hector Altamirano-Medina ${ }^{\mathrm{a}}$, Dimitrios Rovas ${ }^{\mathrm{a}}$, Ian Mawditt ${ }^{\mathrm{b}}$ \\ a Institute for Environmental Design and Engineering ,University College London, London, UK \\ b FourWalls, Bristol, UK
}

\begin{abstract}
Air change rates can be measured using tracer gas techniques which can be costly and intrusive. Moisture data is more accessible, and there is a relationship between moisture conditions and ventilation. This study aims to investigate the relationship between vapour pressure excess and air change rates in bedrooms. The $\mathrm{CO}_{2}$ decay method was used to estimate air change rates when bedrooms were unoccupied in the morning. The relationship between the average hourly change in vapour pressure excess and the air change rate was examined. Results showed a very weak to no correlation between the variables possibly due to moisture buffering and airflow from other rooms.
\end{abstract}

Peer-review under the responsibility of the organizing committee of the ICMB21.

Keywords: vapour pressure excess; moisture excess; moisture supply; air change rate; ventilation; infiltration

\section{Introduction/Background}

There is a drive to improve the airtightness of buildings to reduce heat loss through infiltration. However, there are concerns about the unintended consequences of retrofit, namely the potential of poor ventilation post-retrofit to contribute to moisture problems [1]. The ability to consider a ventilation strategy during retrofit requires knowledge of ventilation rates before and after retrofit. Ventilation is also important for indoor air quality, and tracer gas techniques can be used to measure ventilation rates. However, the temporal and spatial elements of ventilation are difficult to capture using tracer gases [2]. There is a need to develop alternative methods to assess ventilation rates in dwellings, and using vapour pressure excess would be cheaper and less invasive than tracer gas techniques. Vapour pressure excess is effectively a function of moisture generation and ventilation rates, so there is a question as to whether changes in vapour pressure excess can be attributed to changes in ventilation rates (given that moisture generation is known). In dwellings, bedrooms have a predictable pattern of moisture generation as they are usually occupied at night only. The aim of this study was, therefore, to investigate the relationship between vapour pressure excess and air change rates in bedrooms.

\section{Method}

Secondary data for a single dwelling in the UK was analysed from October 2019 to March 2020 which included 5-minute intervals of temperature, relative humidity, $\mathrm{CO}_{2}$, window opening and occupancy in a bedroom. External temperature, relative humidity and $\mathrm{CO}_{2}$ data were also available. As data about moisture generating activities and ventilation was not available, it was decided to use the $\mathrm{CO}_{2}$ decay method to estimate the air change rate [3]. The bedroom would be unoccupied in the morning as indicated by the occupancy sensor, so it was expected that the elevated level of $\mathrm{CO}_{2}$ and vapour pressure (as a result of metabolic generation by occupants) would decay as the source (i.e. occupants) were no longer present. The 'optional' regression method [4] of calculating the air change rate using $\mathrm{CO}_{2}$ decay was used which provided evidence about how constant the air change rate was during the decay period, therefore each decay period could be represented by one air change rate. The relationship between the air change rate and hourly change in vapour pressure excess was examined for infiltration conditions when windows were closed.

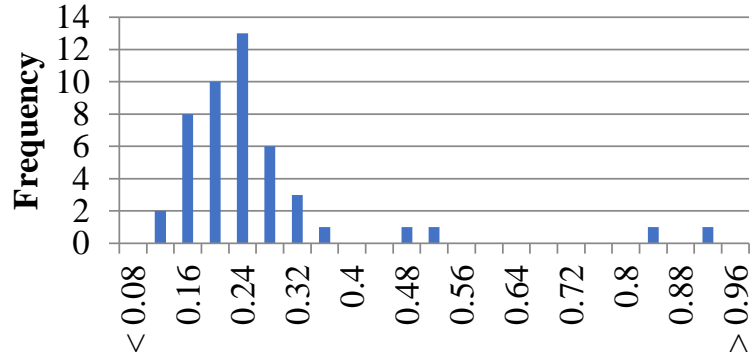

Air changes per hour

Figure 1: Histogram distribution of air change rates calculated from $\mathrm{CO}_{2}$ decays $(\mathrm{N}=47)$.

* Corresponding author. E-mail: ucbqjah@ucl.ac.uk 


\section{Results}

In total, $47 \mathrm{CO}_{2}$ decays were analysed. The median air change rate was 0.21 (IQR: $0.17-0.25$ ) and the distribution is shown in Figure 1, suggesting a non-normal distribution as seen in literature [2]. For each decay period, the average hourly change in vapour pressure excess was calculated with regards to the beginning of the decay. Results are shown in Figure 2, showing that for the majority of mornings, the vapour pressure excess decayed at different rates. For each hour, a Spearman's correlation was carried out to examine whether there was a relationship between the change in vapour pressure excess and air change rate. The Spearman's correlation coefficient $\left(r_{s}\right)$ suggested a very weak to no correlation, and the high $p$-value $(p>0.05)$ suggested the results are not statistically significant.

Table 1: Results of Spearman's correlation between average hourly change in vapour pressure excess and air change rate. During the decay, hours that contained less than six vapour pressure excess measurements were not included hence $\mathrm{N}<47$.

\begin{tabular}{|l|l|l|l|l|l|l|l|l|l|}
\hline & Hour 1 & Hour 2 & Hour 3 & Hour 4 & Hour 5 & Hour 6 & Hour 7 & Hour 8 & Hour 9 \\
\hline $\mathbf{r}_{\mathbf{s}}$ & -0.049 & -0.059 & -0.104 & -0.176 & -0.109 & 0.008 & -0.051 & -0.027 & 0.062 \\
\hline $\mathbf{p}$-value & 0.753 & 0.698 & 0.493 & 0.277 & 0.522 & 0.964 & 0.820 & 0.907 & 0.820 \\
\hline $\mathbf{N}$ & 44 & 45 & 46 & 40 & 37 & 34 & 22 & 21 & 16 \\
\hline
\end{tabular}

\section{Discussion}

During each $\mathrm{CO}_{2}$ decay, the vapour pressure excess did not always decay, as shown in Figure 2. The room was unoccupied so the lack of decay may be due to moisture buffering, the flow of moisture-laden air from other spaces (e.g. bathroom), or changes to the external vapour pressure. Indeed, it has been shown that water vapour is a poor tracer gas when hygroscopic materials are present [5]. Additionally, it is possible that the entire dwelling was not unoccupied and that air from occupied spaces was exchanged with the bedroom. This introduces uncertainty as the assumption that $\mathrm{CO}_{2}$ and moisture generation rates are zero during the analysed decay periods

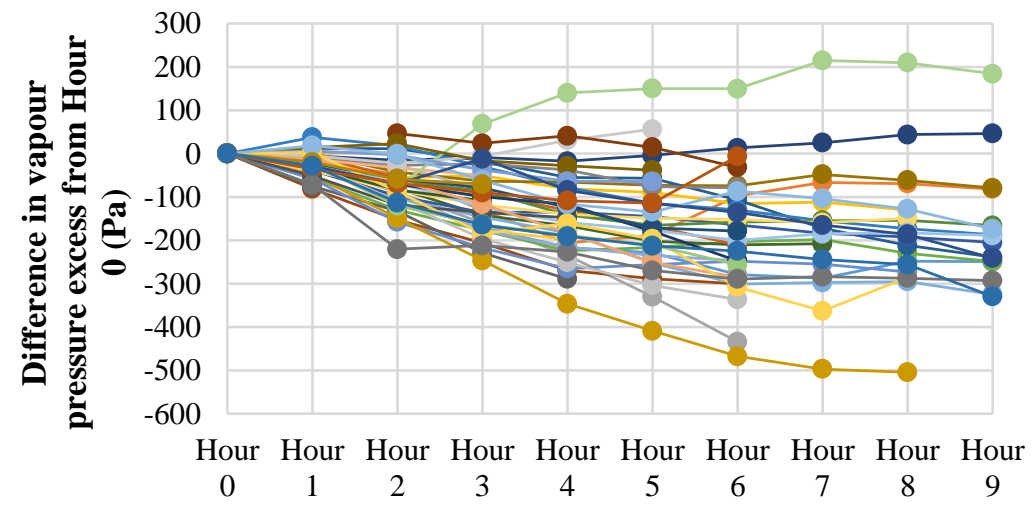
may not be true. This uncertainty can lead to an underestimation of air change rates using the $\mathrm{CO}_{2}$ decay method. In addition, this study focused on infiltration conditions (i.e. when bedroom windows were closed) which means the range of air change rates analysed was small, and differences in vapour pressure excess might only be observed at higher air change rates.

\section{Conclusion}

The Spearman's correlation showed a very weak to no correlation between the air change rate and the change in average hourly vapour pressure excess. The secondary data used was anonymous and lacked context, which introduces uncertainty into the study as both air change rates and moisture conditions in dwellings are influenced by occupants. This reason, along with moisture buffering, may explain why vapour pressure excess did not decay in all cases. However, it is possible that higher air change rates need to be analysed to overcome the uncertainties associated with the $\mathrm{CO}_{2}$ decay method and the impact of moisture buffering.

\section{References}

[1] D. Glew, M. B. Smith, D. Miles-Shenton, and C. Gorse, "Assessing the quality of retrofits in solid wall dwellings," Int. J. Build. Pathol. Adapt., vol. 35, no. 5, pp. 501-518, 2017.

[2] A. K. Persily, "Field measurement of ventilation rates," Indoor Air, vol. 26, no. 1, pp. 97-111, 2016.

[3] R. Claude-Alain and F. Foradini, "Simple and cheap air change rate measurement using CO2 concentration decays," Int. J. Vent., vol. 1, no. 1, pp. 39-44, 2002.

[4] ASTM International, "E741-11: Standard Test Method for Determining Air Change in a Single Zone by Means of a Tracer Gas Dilution,” 2017.

[5] J. C. Giesbrecht, F. A. Curtis, and T. Viraraghavan, "Water vapour as a tracer for ventilation rate measurements," Int. J. Environ. Stud., vol. 56, no. 2, pp. 171-185, 1999. 